Tropical Journal of Pharmaceutical Research May 2015; 14(5): 899-905

ISSN: $1596-5996$ (print); 1596-9827 (electronic)

(C) Pharmacotherapy Group, Faculty of Pharmacy, University of Benin, Benin City, 300001 Nigeria.

All rights reserved.

Available online at http://www.tjpr.org

Original Research Article

http://dx.doi.org/10.4314/tjpr.v14i5.21

\title{
Plasma Pharmacokinetic and Heart Distribution Studies of Z-GP-EPI, a Hypocardiotoxic Prodrug of Epirubicin
}

\author{
Guangquan Liu, Enpan Mo, Xiaoxiong Wang, Nong Wu, Fanglan Liu, Weiqi \\ Yuan, Huaqing Chen, Jingjing Wang, Jun $\mathrm{Xu}$ and Shaohui Cai* \\ College of Pharmacy, Jinan University, Guangzhou 510632, China
}

*For correspondence: Email: csh5689@sina.com, goldstar_8209@163.com; Tel: +86-020-85228025, +86-020-85223704; Fax: $+86-020-85224766$

Received: 12 February 2015

Revised accepted: 26 April 2015

\begin{abstract}
Purpose: To explore the plasma pharmacokinetics and heart distribution of Z-GP-EPI, a low cardiotoxic prodrug of epirubicin (EPI).

Methods: The drugs were administered to 20 rats $(11.22,44 \mu \mathrm{mol} / \mathrm{kg})$ by intravenous injection and 70 mice $(30 \mu \mathrm{mol} / \mathrm{kg})$ by tail intravenous injection. The profiles of Z-GP-EPI and EPI in rat plasma or mice heart were determined by high performance liquid chromatography (HPLC) method, which employed the Octadecylsilyl (ODS) column with a mobile phase of acetonitrile : $0.1 \%$ trifluoroacetic-water (42:58, $V / V)$ at a flow rate of $1.0 \mathrm{~mL} / \mathrm{min}$ and an ultraviolet (UV) detector at a wavelength of $495 \mathrm{~nm}$. Pharmacokinetics parameters were calculated using a pharmacokinetic software.

Results: Relative standard deviation (RSD) of intra- and inter-day precision values was $<15 \%$ in each case while method accuracy with recovery was between 85 and $110 \%$ for plasma and heart samples. After administration of 22 umol/kg Z-GP-EPI or EPI, terminal elimination half-life (t1/2) of Z-GP-EPI $(1.41 \mathrm{~h})$ was smaller than that of EPI (12.24 h). Furthermore, the concentration of Z-GP-EPI in heart rapidly decreased from $17.3 \mu \mathrm{g} / \mathrm{g}(0.05 \mathrm{~h})$ to undetectable levels $(2 \mathrm{~h})$ while EPI changed from $14.3 \mu \mathrm{g} / \mathrm{g}$ (0.05 h) to $9.5 \mu \mathrm{g} / \mathrm{g}(2 \mathrm{~h})$.

Conclusion: The HPLC method established in this study is a feasible approach to detecting Z-GP-EPI and EPI in plasma and heart tissue. In addition, Z-GP-EPI is eliminated more rapidly from plasma and heart tissue than EPI, which probably contributes to the low cardiotoxicity of Z-GP-EPI.
\end{abstract}

Keywords: N-Benzyloxycarbony-prolinyl-glycinyl epirubicin (Z-GP-EPI), Epirubicin, Prodrug, Hypocardiotoxic, Pharmacokinetics, Heart distribution

Tropical Journal of Pharmaceutical Research is indexed by Science Citation Index (SciSearch), Scopus, International Pharmaceutical Abstract, Chemical Abstracts, Embase, Index Copernicus, EBSCO, African Index Medicus, JournalSeek, Journal Citation Reports/Science Edition, Directory of Open Access Journals (DOAJ), African Journal Online, Bioline International, Open-J-Gate and Pharmacy Abstracts

\section{INTRODUCTION}

EPI possesses broad-spectrum antineoplastic activity [1]. However, the cardio- toxicity associated with EPI is cumulative and doselimiting, thus hampering its use in the clinic [2]. There are considerable efforts to improve the selectivity of anthracycline antibiotics and reduce their toxicity using nontoxic prodrugs. Such prodrugs are preferentially converted into active anticancer agents at the tumor site, where drugconverting enzymes are expressed at significantly higher levels than in normal tissues [3-6]. Fibroblast activation protein a (FAPa), a serine protease [7], is expressed in over $90 \%$ of the stroma of malignant epithelial tumors, but not in normal tissues [8-10].

Given this, we have designed an EPI prodrug using the FAP-specific dipeptides glutamine $(Z)$, glycine $(G)$, and proline $(P)$, and named it Z-GP- 
EPI. In previous studies we have demonstrated that Z-GP-EPI could show similar inhibition activity to the growth of tumor in tumor-bearing mice model compared with EPI. Meanwhile, it could reduce the myocardial toxicity, which was the main adverse side effect of EPI, and didn't show obvious toxicity to other tissues. In addition, it is generally believed that the pharmacokinetic properties of a drug are closely linked to its efficacy and toxicity [11-14].

Therefore, the objective of this study was to explore the plasma pharmacokinetics and heart distribution of Z-GP-EPI and compare them with those of EPI.

\section{EXPERIMENTAL}

\section{Animals}

Male, specific pathogen-free (SPF) SpragueDawley rats (weighing $250 \pm 50 \mathrm{~g}$ ) and female SPF Bal b/c mice $(20 \pm 2 \mathrm{~g})$ were purchased from Medical Experimental Animal Center of Guangdong, China. Animal production license NO. SCXK (Yue) 2008 - 0002. All the animals were housed in an air-conditioned animal quarter at a temperature of $25 \pm 2{ }^{\circ} \mathrm{C}$ and a relative humidity of $75 \pm 5 \%$, and kept on $12 \mathrm{~h}$ light/12 h dark cycle with free access to food. Before the experiment, the animals were fasted overnight for $12 \mathrm{~h}$ and provided water ad libitum. All animal experiments were approved by the ethical committee of Institute of Laboratory Animal Science, Jinan University (License no. SYXK (Yue) 2012 - 0117). The animals were handled according to standard protocols for the use of laboratory animals [15].

\section{Chemicals and reagents}

The preparation of Z-GP-EPI (purity > $99.0 \%$ ) was accomplished by the College of Pharmacy, SunYat-sen University (Guangzhou, China). EPI hydrochloride (EPI - $\mathrm{HCl}$ ) was purchased from Hisun Pharmaceutical (purity $>98 \%$, Zhejiang, China). Daunorubicin (DNR; purity > $91.0 \%$ ), used as the internal standard in the study, was provided by the National Institute for Food and Drug Control, China. High-performance liquid chromatography (HPLC) - grade methanol and acetonitrile were provided by Jiangsu Hanbon (Jiangsu, China). HPLC-grade trifluoroacetic acid was purchased from Guangzhou Dongzheng Chemical Glass Instrument (Guangdong, China). All other chemicals and reagents at the highest grade available were obtained from Guangzhou Dongzheng Chemical Glass Instrument (Guangdong, China). Distilled water was produced in the Laboratory of Pharmacy.

\section{Chromatography}

The chromatographic analysis was performed by a 1260 Agilent chromatographic system (USA) with UV detector. The detection wavelength was $495 \mathrm{~nm}$. Ultimate XB-C18 (4.6 × $250 \mathrm{~mm}, 5 \mu \mathrm{m}$, Welch materials) was used as analytical column with elution mobile phase was acetonitrile: $0.1 \%$ trifluoroacetic-water $(42: 58, \mathrm{v} / \mathrm{v})$ at a flow rate of $1.0 \mathrm{~mL} / \mathrm{min}$, column temperature $25^{\circ} \mathrm{C}$.

\section{Pretreatment of plasma samples and heart tissues}

A plasma sample $(200 \mu \mathrm{L})$ was mixed with $20 \mu \mathrm{L}$ of DNR $(5 \mu \mathrm{g} / \mathrm{mL}$ for EPI analyses and $8 \mu \mathrm{g} / \mathrm{mL}$ for Z-GP-EPI analyses); the heart tissues were homogenized in lysis buffer [16]. Then $400 \mu \mathrm{L}$ of homogenate were mixed with $40 \mu \mathrm{L}$ of the internal standard DNR $(10 \mu \mathrm{g} / \mathrm{mL})$. These samples were treated as the following liquidliquid extraction procedure: the samples were mixed with $3 \mathrm{~mL}$ of the extraction solution (methanol : acetonitrile : dichloromethane 1 : $: 2: 8$, $\mathrm{v} / \mathrm{v} / \mathrm{v})$ ) and then centrifuged for $15 \mathrm{~min}$ at 3000 rpm and room temperature $\left(25{ }^{\circ} \mathrm{C}\right)$. The supernatant was transferred to a clean tube and dried by $55^{\circ} \mathrm{C}$ nitrogen stream. The residue was reconstituted in $100 \mu \mathrm{L}$ of methanol; $20 \mu \mathrm{L}$ of the final sample was injected for HPLC analysis.

\section{Method validation}

To quantify the Z-GP-EPI and EPI concentrations in plasma and heart tissue samples, the aforementioned HPLC method was validated in accordance with the United States Food and Drug Administration guidelines for specificity, extraction recovery, linearity, intra- and inter-day precision and accuracy.

\section{Plasma pharmacokinetic studies}

Sprague-Dawley rats were randomly divided into 4 groups of 5 rats each and treated as follows: Group A: $22 \mu \mathrm{mol} / \mathrm{kg}$ EPI; Group B: $11 \mu \mathrm{mol} / \mathrm{kg}$ Z-GP-EPI; Group C: $22 \mu \mathrm{mol} / \mathrm{kg}$ Z-GP-EPI; Group D: $44 \mu \mathrm{mol} / \mathrm{kg}$ Z-GP-EPI. Rats in Group $A-D$ were treated by intravenous injection at a dose equivalent to various $\mu \mathrm{mol}$ drugs per kilogram body weight. Before $24 \mathrm{~h}$ of the experiment, jugular vein intubation was performed on each rat. In the experiment, blood samples $(0.5 \mathrm{~mL})$, which were centrifuged for 5 $\mathrm{min}$ at $3000 \mathrm{rpm}$ to obtain plasma samples, were drawn from the jugular vein at $0,0.05,0.1,0.17$, $0.34,0.76,1,2,4,6$, and $8 \mathrm{~h}$ after drug administration. Simultaneously, an identical volume of saline was administered to maintain total body fluid balance. Then the blood samples 
were pretreated as the method mentioned above. After determination of EPI and Z-GP-EPI concentration, their main pharmacokinetic parameters were calculated by pharmacokinetic software DAS 3.0 .

\section{Drug distribution in the heart}

The Bal b/c mice were randomly divided into 2 groups of 35 mice each and treated as follows: Group A' : $30 \mu \mathrm{mol} / \mathrm{kg}$ EPI and Group B' : 30 $\mu \mathrm{mol} / \mathrm{kg}$ Z-GP-EPI. Mice of Group A' and B' were treated by tail intravenous injection at a dose of $30 \mu \mathrm{mol}$ EPI or Z-GP-EPI per kilogram body weight, which was equivalent to $22 \mu \mathrm{mol} E P I$ or Z-GP-EPI per kilogram weight when administered into rats. After intravenous injection of EPI or Z-GP-EPI, 5 mice were euthanized for each time points at $0.05,0.167,0.5,2,4,8,12 \mathrm{~h}$ in each group. The heart was removed, washed with physiological saline, and blotted onto filter papers. Then the heart tissue samples were pretreated as the method mentioned above. After determination of EPI and Z-GP-EPI concentration by HPLC, the comparison of concentration between EPI and Z-GP-EPI was carried out to describe their different distribution in heart tissue.

\section{Statistical analysis}

Values are expressed as mean \pm standard deviation (SD). The data for drug distribution in heart were evaluated by one-way ANOVA followed by Dunnett Multiple Comparison test between different groups. Statistical significance of differences was analyzed using SPSS software (SPSS for Windows 15.0, SPSS Inc, USA) at a significance level of $p<0.05$.

\section{RESULTS}

\section{Validation results}

Fig 1 and 2 illustrated the representative HPLC chromatograms of Z-GP-EPI, EPI, and the internal standard DNR in plasma samples and heart tissues. The results showed good resolution with no interfering peaks among the plasma samples and heart tissue of the Z-GPEPI, EPI, and DNR (internal standard) groups. The extraction recoveries of Z-GP-EPI, EPI, and DNR were listed in Tab 1, which indicated that they were all more than $85 \%$ at various concentrations in plasma and heart tissues. Tab 2 illustrated the calibration curves of Z-GP-EPI and EPI in plasma samples $\left(0.1-100 \mu \mathrm{g} / \mathrm{mL}, \mathrm{R}^{2}=\right.$ $\left.0.999,0.01-20 \mu \mathrm{g} / \mathrm{mL}, R^{2}=0.998\right)$ and heart tissue $\left(0.5-50 \mu \mathrm{g} / \mathrm{mL}, R^{2}=0.998,0.5-20\right.$ $\left.\mu \mathrm{g} / \mathrm{mL}, \mathrm{R}^{2}=0.999\right)$. Moreover, the precision and accuracy results obtained were presented in Tab 3 . The results showed that RSD \% of intra- and inter-day precision values were less than $15 \%$ (RSD) and method accuracy with recoveries were between $85 \%$ - $110 \%$ for the plasma and heart samples. The Tab 4 and 5 showed the results of stability for Z-GP-EPI or EPI in plasma and heart tissues. The results illustrated the recoveries were more than $85 \%$ at $4{ }^{\circ} \mathrm{C}$ and 90 $\%$ at $-80^{\circ} \mathrm{C}$ but less than $80 \%$ at $25^{\circ} \mathrm{C}$.

\section{Z-GP-EPI is eliminated more rapidly than EPI in plasma}

The main pharmacokinetic parameters of Z-GPEPI and EPI in plasma were summarized in Tab 6. As shown, the mean $\mathrm{AUC}_{0-\infty}$ of Z-GP-EPI was $3.93 \mu \mathrm{g} \cdot \mathrm{mL}^{-1} \cdot \mathrm{h}^{-1}$ and the $\mathrm{t}_{1 / 2}$ was $1.41 \mathrm{~h}$ with $\mathrm{MRT}_{0-\infty}$ of $0.97 \mathrm{~h}$, while the mean $\mathrm{AUC}_{0-\infty}$ of $\mathrm{EPI}$ was $2.84 \mu \mathrm{g} \cdot \mathrm{mL}^{-1} \cdot \mathrm{h}^{-1}$ and the $\mathrm{t}_{1 / 2}$ was $12.24 \mathrm{~h}$ with $\mathrm{MRT}_{0-\infty}$ of $7.9 \mathrm{~h}$. The CL of Z-GP-EPI was $6.24 \mathrm{~L} \cdot \mathrm{kg}^{-1} \cdot \mathrm{h}^{-1}$ with $\mathrm{V}_{\mathrm{d}}$ of $5.46 \mathrm{~L} / \mathrm{kg}$, while that of

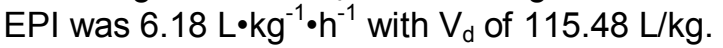

\section{Z-GP-EPI eliminated more rapidly than EPI in heart}

Fig 3 illustrates the concentration of Z-GP-EPI and EPI in heart tissues at different time after intravenous administration of Z-GP-EPI and EPI. The results showed that the concentration of ZGP-EPI quickly decrease from $17.3 \mu \mathrm{g} / \mathrm{g}$ at 0.05 $\mathrm{h}$ to undetectable concentration at $2 \mathrm{~h}$. However, the concentrations of EPI change from $14.3 \mu \mathrm{g} / \mathrm{g}$ at $0.05 \mathrm{~h}$ to $9.5 \mu \mathrm{g} / \mathrm{g}$ at $2 \mathrm{~h}$. Even at $12 \mathrm{~h}$ after administration, the concentration of EPI was still $2.4 \mu \mathrm{g} / \mathrm{g}$.

\section{DISCUSSION}

The low cardiotoxicity of Z-GP-EPI was vilified by our previous in vivo experiment. However, the bioanalytic method of Z-GP-EPI in vivo was still unclear. In view of the relationship between toxicity and pharmacokinetic, the HPLC method for detecting Z-GP-EPI in vivo was established in this study. Moreover, the plasma pharmacokinetic and heart distribution of Z-GP-EPI was calculated to support the result of low cardiotoxicity from in vivo experiment.

According to criteria of United States Food and Drug Administration guidelines, a suitable bioanalytic method should be specified, linear, precise and accurate. The HPLC method established in this study show good resolution between Z-GP-EPI, EPI and DNR as well as the 

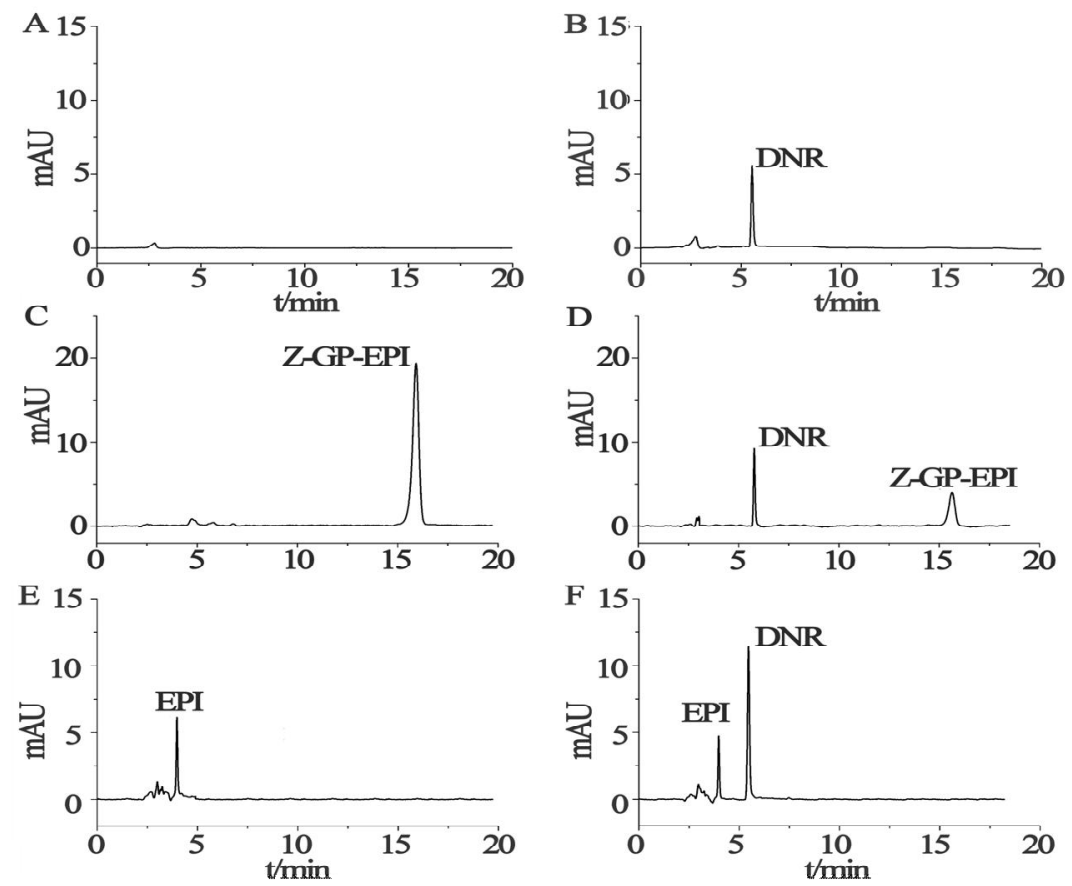

Figure 1: The representative HPLC chromatograms of Z-GP-EPI, EPI, and the internal standard DNR in plasma samples. (A. blank plasma; B. blank plasma spiked with DNR; C. blank plasma spiked with Z-GP-EPI; D. plasma sample(taken $1 \mathrm{~h}$ after jugular vein administration of Z-GP-EPI) spiked with DNR; E. blank plasma spiked with $\mathrm{EPI}$; F. plasma sample(1 $\mathrm{h}$ after jugular vein administration of EPI) spiked with DNR)
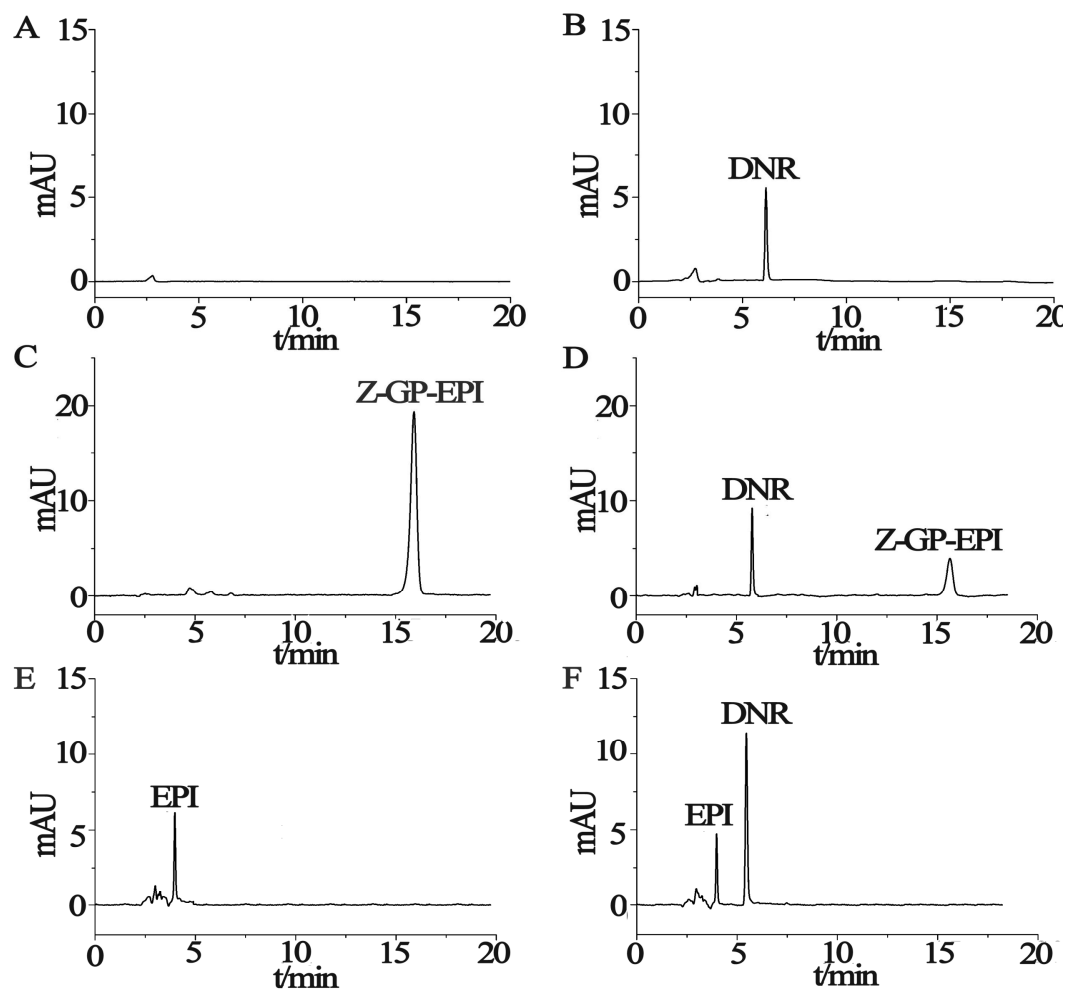

Figure 2: The representative HPLC chromatograms of Z-GP-EPI, EPI, and the internal standard DNR in heart tissue samples. (A. blank heart tissue; B. blank heart tissue spiked with DNR; C. blank heart tissue spiked with ZGP-EPI; D. heart tissue sample(taken $0.5 \mathrm{~h}$ after jugular vein administration of Z-GP-EPI) spiked with DNR; E. blank heart tissue spiked with EPI; F. heart tissue sample(12 h after jugular vein administration of EPI) spiked with DNR) 
Table 1: Extraction recovery of Z-GP-EPI, EPI, and DNR $(n=5)$

\begin{tabular}{lcccc}
\hline \multirow{2}{*}{ Variable } & \multicolumn{2}{c}{ Administered $(\boldsymbol{\mu g} / \mathbf{m L})$} & \multicolumn{2}{c}{ Extraction recovery, mean \pm SD \% } \\
\cline { 2 - 5 } & Plasma & Heart & Plasma & Heart \\
\hline \multirow{2}{*}{ Z-GP-EPI } & 0.2 & 0.8 & $103.62 \pm 3.50$ & $85.60 \pm 4.24$ \\
& 5 & 5 & $86.95 \pm 0.35$ & $89.78 \pm 2.91$ \\
\multirow{2}{*}{ EPI } & 80 & 45 & $106.83 \pm 1.15$ & $94.19 \pm 2.43$ \\
& 0.02 & 0.8 & $95.71 \pm 0.91$ & $92.61 \pm 1.91$ \\
DNR & 5 & 5 & $85.45 \pm 0.29$ & $95.35 \pm 2.36$ \\
\hline$R S D=$ relative standard deviation & 15 & $91.89 \pm 0.90$ & $105.32 \pm 3.60$ \\
& 15 & 1 & $85.65 \pm 0.77$ & $87.76 \pm 0.57$ \\
\hline
\end{tabular}

Table 2: Linear regression equations for Z-GP-EPI and EPI $(n=7)$

\begin{tabular}{lcccc}
\hline Variable & & Regression equation & $\mathbf{R}^{2}$ & Range, $\boldsymbol{\mu g} / \mathbf{m L}$ \\
\hline \multirow{2}{*}{ Z-GP-EPI } & Plasma & $y=0.921 x+0.043$ & 0.999 & $0.1-100$ \\
& Heart & $y=0.731 x-0.057$ & 0.998 & $0.5-50$ \\
EPI & Plasma & $y=1.351 x+0.002$ & 0.998 & $0.01-20$ \\
& Heart & $y=0.492 x-0.002$ & 0.999 & $0.5-20$ \\
\hline
\end{tabular}

Table 3: Precision and accuracy for Z-GP-EPI and EPI $(n=5)$

\begin{tabular}{|c|c|c|c|c|c|}
\hline \multirow[t]{2}{*}{ Variable } & & \multirow[t]{2}{*}{$\begin{array}{l}\text { Administered } \\
(\mu \mathrm{g} / \mathrm{mL})\end{array}$} & \multicolumn{2}{|c|}{ Precision/RSD \% } & \multirow[t]{2}{*}{$\begin{array}{c}\text { Recovery } \\
(\%, \text { mean } \pm \text { SD })\end{array}$} \\
\hline & & & Intra- & Inter- & \\
\hline \multirow{6}{*}{ Plasma } & \multirow{3}{*}{ Z-GP-EPI } & 0.2 & 8.13 & 12.08 & $102.68 \pm 10.47$ \\
\hline & & 5 & 5.92 & 5.49 & $98.01 \pm 1.00$ \\
\hline & & 80 & 8.74 & 5.63 & $93.40 \pm 5.32$ \\
\hline & \multirow{3}{*}{ EPI } & 0.02 & 6.95 & 6.41 & $107.46 \pm 0.95$ \\
\hline & & 5 & 7.71 & 2.18 & $111.82 \pm 0.72$ \\
\hline & & 15 & 2.31 & 5.78 & $104.53 \pm 1.22$ \\
\hline \multirow{6}{*}{ Heart } & \multirow{3}{*}{ Z-GP-EPI } & 0.8 & 7.57 & 11.67 & $93.17 \pm 0.89$ \\
\hline & & 5 & 6.41 & 5.32 & $98.36 \pm 1.54$ \\
\hline & & 45 & 2.45 & 3.34 & $89.76 \pm 3.87$ \\
\hline & \multirow{3}{*}{ EPI } & 0.8 & 9.59 & 8.75 & $88.36 \pm 2.67$ \\
\hline & & 5 & 4.51 & 6.07 & $94.62 \pm 1.05$ \\
\hline & & 15 & 8.06 & 5.54 & $95.36 \pm 0.97$ \\
\hline
\end{tabular}

Table 4: Stability for Z-GP-EPI and EPI in plasma $(n=5)$

\begin{tabular}{|c|c|c|c|c|c|}
\hline Variable & $\begin{array}{c}\text { Administered } \\
(\mu \mathrm{g} / \mathrm{mL})\end{array}$ & Time & $\begin{array}{c}25^{\circ} \mathrm{Cl} \\
\text { mean } \pm \text { SD \% }\end{array}$ & $\begin{array}{c}4^{\circ} \mathrm{Cl} \\
\text { mean } \pm \text { SD \% }\end{array}$ & $\begin{array}{c}-80^{\circ} \mathrm{Cl} \\
\text { mean } \pm \text { SD \% }\end{array}$ \\
\hline \multirow{6}{*}{ Z-GP-EPI } & \multirow{2}{*}{0.2} & $12 \mathrm{~h}$ or $30 \mathrm{~d}$ & $32.75 \pm 0.22$ & $90.27 \pm 0.74$ & $95.17 \pm 0.76(30 d)$ \\
\hline & & $24 \mathrm{~h}$ or $90 \mathrm{~d}$ & $25.39 \pm 0.46$ & $91.43 \pm 0.91$ & $91.84 \pm 0.51(90 \mathrm{~d})$ \\
\hline & \multirow[b]{2}{*}{5} & $12 \mathrm{~h}$ or $30 \mathrm{~d}$ & $40.21 \pm 0.42$ & $95.48 \pm 0.12$ & $89.43 \pm 0.25(30 \mathrm{~d})$ \\
\hline & & $24 \mathrm{~h}$ or $90 \mathrm{~d}$ & $31.90 \pm 0.48$ & $87.15 \pm 0.33$ & $98.52 \pm 0.14(90 d)$ \\
\hline & \multirow{2}{*}{80} & $12 \mathrm{~h}$ or $30 \mathrm{~d}$ & $52.94 \pm 0.64$ & $112.68 \pm 0.92$ & $103.58 \pm 0.79(30 d)$ \\
\hline & & $24 \mathrm{~h}$ or $90 \mathrm{~d}$ & $42.63 \pm 0.77$ & $83.25 \pm 1.27$ & $88.79 \pm 0.47(90 \mathrm{~d})$ \\
\hline \multirow{6}{*}{ EPI } & \multirow{2}{*}{0.02} & $12 \mathrm{~h}$ or $30 \mathrm{~d}$ & $53.49 \pm 0.32$ & $100.61 \pm 0.21$ & $93.48 \pm 1.01(30 \mathrm{~d})$ \\
\hline & & $24 \mathrm{~h}$ or $90 \mathrm{~d}$ & $23.38 \pm 0.57$ & $93.43 \pm 0.63$ & $93.69 \pm 2.07(90 \mathrm{~d})$ \\
\hline & \multirow{2}{*}{1} & $12 \mathrm{~h}$ or $30 \mathrm{~d}$ & $64.99 \pm 1.01$ & $80.94 \pm 0.32$ & $93.69 \pm 0.98(30 d)$ \\
\hline & & $24 \mathrm{~h}$ or $90 \mathrm{~d}$ & $41.98 \pm 0.99$ & $81.38 \pm 0.55$ & $91.74 \pm 0.70(90 d)$ \\
\hline & \multirow{2}{*}{15} & $12 \mathrm{~h}$ or $30 \mathrm{~d}$ & $79.42 \pm 0.71$ & $94.30 \pm 0.70$ & $91.74 \pm 1.42(30 d)$ \\
\hline & & $24 \mathrm{~h}$ or $90 \mathrm{~d}$ & $54.12 \pm 0.52$ & $87.02 \pm 0.45$ & $105.20 \pm 1.49(90 d)$ \\
\hline
\end{tabular}


Table 5: Stability for Z-GP-EPI and EPI in heart $(n=5)$

\begin{tabular}{|c|c|c|c|c|c|}
\hline Variable & $\begin{array}{c}\text { Administere } \\
\text { d }(\mu \mathrm{g} / \mathrm{mL})\end{array}$ & Time & $\begin{array}{c}25^{\circ} \mathrm{Cl} \\
(\%, \text { mean } \pm S D)\end{array}$ & $\begin{array}{c}4^{\circ} \mathrm{C} / \\
(\%, \text { meantSD) }\end{array}$ & $\begin{array}{c}-80^{\circ} \mathrm{C} / \\
(\%, \text { mean } \pm S D)\end{array}$ \\
\hline \multirow[t]{6}{*}{ Z-GP-EPI } & \multirow{2}{*}{0.8} & $12 \mathrm{~h}$ or $30 \mathrm{~d}$ & $25.13 \pm 0.79$ & $89.55 \pm 2.04$ & $94.33 \pm 0.46(30 \mathrm{~d})$ \\
\hline & & $24 \mathrm{~h}$ or $90 \mathrm{~d}$ & $21.37 \pm 0.62$ & $85.43 \pm 1.09$ & $92.59 \pm 0.31(90 \mathrm{~d})$ \\
\hline & \multirow{2}{*}{5} & $12 \mathrm{~h}$ or $30 \mathrm{~d}$ & $41.39 \pm 0.73$ & $93.05 \pm 1.11$ & $87.22 \pm 0.98(30 d)$ \\
\hline & & $24 \mathrm{~h}$ or $90 \mathrm{~d}$ & $37.11 \pm 0.92$ & $86.33 \pm 0.33$ & $97.44 \pm 0.73(90 \mathrm{~d})$ \\
\hline & \multirow{2}{*}{45} & $12 \mathrm{~h}$ or $30 \mathrm{~d}$ & $26.41 \pm 0.72$ & $105.68 \pm 1.86$ & $101.39 \pm 1.91(30 d)$ \\
\hline & & $24 \mathrm{~h}$ or $90 \mathrm{~d}$ & $21.64 \pm 0.86$ & $93.14 \pm 2.75$ & $95.62 \pm 0.81(90 d)$ \\
\hline \multirow[t]{6}{*}{ EPI } & \multirow{2}{*}{0.8} & $12 \mathrm{~h}$ or $30 \mathrm{~d}$ & $49.55 \pm 0.13$ & $104.54 \pm 0.77$ & $95.38 \pm 0.51(30 d)$ \\
\hline & & $24 \mathrm{~h}$ or $90 \mathrm{~d}$ & $31.89 \pm 0.08$ & $90.80 \pm 0.46$ & $93.11 \pm 0.43(90 \mathrm{~d})$ \\
\hline & \multirow{2}{*}{5} & $12 \mathrm{~h}$ or $30 \mathrm{~d}$ & $70.65 \pm 0.09$ & $86.32 \pm 1.01$ & $98.72 \pm 1.18(30 \mathrm{~d})$ \\
\hline & & $24 \mathrm{~h}$ or $90 \mathrm{~d}$ & $50.77 \pm 2.06$ & $84.24 \pm 1.03$ & $90.51 \pm 0.95(90 d)$ \\
\hline & \multirow{2}{*}{15} & $12 \mathrm{~h}$ or $30 \mathrm{~d}$ & $73.21 \pm 0.55$ & $89.62 \pm 0.51$ & $91.74 \pm 1.02(30 \mathrm{~d})$ \\
\hline & & $24 \mathrm{~h}$ or $90 \mathrm{~d}$ & $51.44 \pm 0.69$ & $86.02 \pm 0.93$ & $105.20 \pm 1.49(90 \mathrm{~d})$ \\
\hline
\end{tabular}

Table 6: Plasma pharmacokinetic parameters for Z-GP-EPI and EPI

\begin{tabular}{lcc}
\hline Parameter & Z-GP-EPI (mean \pm SD) & EPI (mean \pm SD) \\
\hline AUC $_{0-8}\left(\mu \mathrm{g} \cdot \mathrm{mL}^{-1} \cdot \mathrm{h}^{-1}\right)$ & $3.90 \pm 1.97$ & $2.43 \pm 0.30$ \\
AUC $_{0-\infty}\left(\mu \mathrm{g} \cdot \mathrm{mL}^{-1} \cdot \mathrm{h}^{-1}\right)$ & $3.93 \pm 2.17$ & $2.84 \pm 0.44$ \\
\hline $\mathrm{MRT}_{0-8}(\mathrm{~h})$ & $0.74 \pm 0.21$ & $1.77 \pm 0.30$ \\
$\mathrm{MRT}_{0-\infty}(\mathrm{h})$ & $0.97 \pm 0.52$ & $7.90 \pm 1.58$ \\
\hline $\mathrm{CL}\left(\mathrm{L} \cdot \mathrm{kg}^{-1} \cdot \mathrm{h}^{-1}\right)$ & $6.24 \pm 1.56$ & $6.18 \pm 1.68$ \\
$\mathrm{~V}_{\mathrm{d}}(\mathrm{L} / \mathrm{kg})$ & $5.46 \pm 2.80$ & $115.48 \pm 11.43$ \\
$\mathrm{t}_{1 / 2}(\mathrm{~h})$ & $1.41 \pm 0.53$ & $12.24 \pm 2.57$ \\
\hline
\end{tabular}

*22 $\mu \mathrm{mol} / \mathrm{kg}$ dose; $A U C=$ area under the concentration-time curve; $C L=$ clearance; $M R T=$ mean residence time; $t_{1 / 2}=$ terminal elimination half-life; $V_{d}=$ apparent volume of distribution

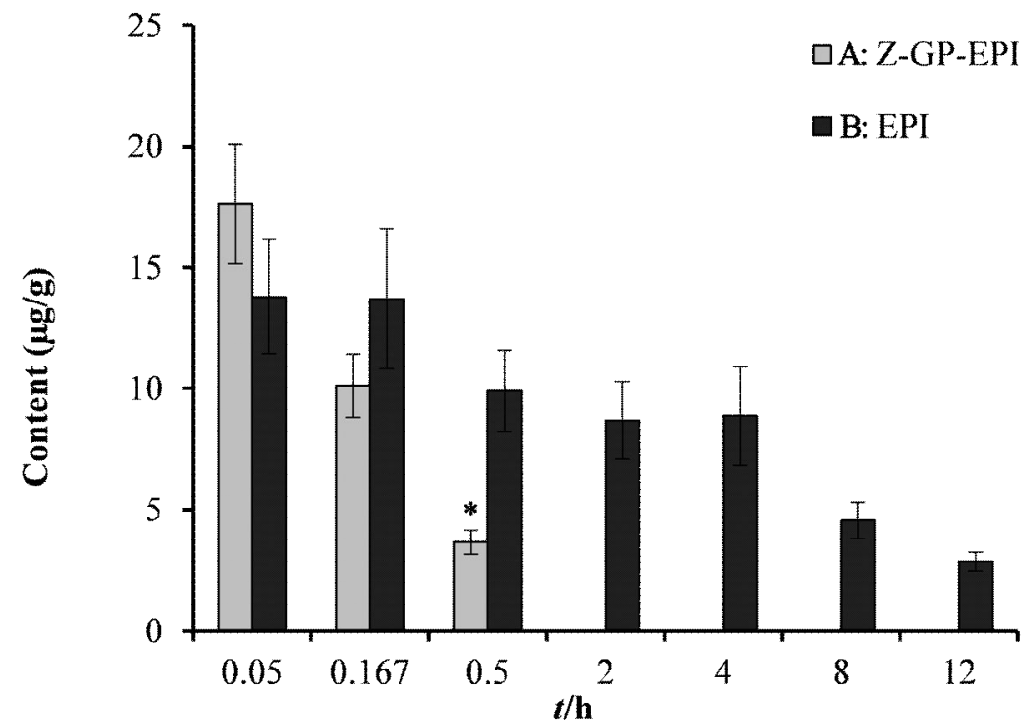

Figure 3: Concentrations of Z-GP-EPI and EPI in heart tissues after intravenous administration ( ${ }^{*}: \mathrm{P}<0.05$ vs. EPI). A: The mice in this group were injected with Z-GP-EPI $(30 \mu \mathrm{mol} / \mathrm{kg})$. B: The mice in this group were injected with $\mathrm{EPI}(30 \mu \mathrm{mol} / \mathrm{kg})$

linear correlation between concentration and peak area at range $0.01-20 \mu \mathrm{g} / \mathrm{mL}$ in plasma and $0.5-20 \mu \mathrm{g} / \mathrm{mL}$ in heart tissue for EPI, 0.1 $100 \mu \mathrm{g} / \mathrm{mL}$ in plasma and $0.5-50 \mu \mathrm{g} / \mathrm{mL}$ in heart tissue for Z-GP-EPI, respectively. Meanwhile, intra- and inter-day precision, extraction recovery and accuracy are all match the criteria. Thus the bioanalytic method was considered to be a feasible method to determine content of Z-GP.
EPI and EPI in plasma and heart tissues. Then the stability of Z-GP-EPI and EPI were also evaluated by the established method in this study, result claimed that Z-GP-EPI and EPI were not stable at room temperature for the mean recoveries from the nominal concentrations declined to less than $80 \%$. This indicates that the plasma and heart samples 
should be stored in $4{ }^{\circ} \mathrm{C}$ or $-80^{\circ} \mathrm{C}$ immediately after collection.

After confirmation of the bioanalytic method of ZGP-EPI and EPI, the plasma pharmacokinetic of Z-GP-EPI and EPI were calculated and compared. No significant difference was observed in AUC and CL between Z-GP-EPI and EPI. Smaller $M R T_{0-\infty}, t_{1 / 2}$ and $V_{d}$ of Z-GP-EPI suggest that it might be distributed into organization faster or a quicker elimination process. Then we further determined the heart distribution of Z-GP-EPI and EPI, the result show Z-GP-EPI obviously eliminate more quickly than EPI in heart tissues. Z-GP-EPI could not be detected at even $2 \mathrm{~h}$ after administration. Meanwhile, we didn't detect free EPI enzymolysised from Z-GP-EPI in heart tissues at $2 \mathrm{~h}$. However, EPI could still be detected at $12 \mathrm{~h}$ after administration of EPI $(30 \mu \mathrm{mol} / \mathrm{kg})$. The difference of elimination between Z-GP-EPI and EPI in heart tissues might support the low cardiotoxicity of Z-GP-EPI concluded from our previous in vivo studies. Next stage, PBPK model of Z-GP-EPI would be constructed for plasma and main organizations to clearly describe the ADMET of Z-GP-EPI.

\section{CONCLUSION}

The results obtained in this work are noteworthy as they indicate that the developed HPLC assay method for Z-GP-EPI and EPI is feasible. The results also demonstrate that the cardiotoxicity of $Z$-GP-EPI is lower than that of EPI. These findings provide a basis for the future study of $Z$ GP-EPI and its inclusion in cancer therapeutic regimens.

\section{ACKNOWLEDGEMENT}

This work was financially supported by grants from National Natural Science Foundation of China (nos. 30973565, 81273538, and 81202461), National Important Technology Project "Creation of Major New Drugs" (no. 2009ZX09103 - 040) and China Postdoctoral Science Foundation (no. 2013M531906).

\section{REFERENCES}

1. Hortobagyi, G. Anthracyclines in the treatment of cancer. Drugs 1997; 54: 1-7.

2. Lenaz L, Page JA. Cardiotoxicity of adriamycin and related anthracyclines. Cancer Treat Rev 1976; 3(3): 111.
3. Devalapally $H$, Rajan KS, Akkinepally RR, Devarakonda RK. Safety pharmacokinetics and biodistribution studies of a $\beta$-galactoside prodrug of doxorubicin for improvement of tumor selective chemotherapy. Drug Dev Ind Pharm 2008; 34: 789-795.

4. Minotti G, Menna $P$, Salvatorelli E, Cairo G, Gianni L. Anthracyclines: molecular advances and pharmacologic developments in antitumor activity and cardiotoxicity. Pharmacol Rev 2004; 56(2): 185-229.

5. Danesi R, Fogli $S$, Gennari A, Conte $P$, Tacca MD. Pharmacokinetic-pharmacodynamic relationships of the anthracycline anticancer drugs. Clin Pharmacokinet 2002: 41(6): 431-444.

6. Rivera E. Liposomal anthracyclines in metastatic breast cancer: Clinical update. Oncologist 2003; 8: 3-9.

7. Chen WT, Kelly $T$. Seprase complexes in cellular invasiveness. Cancer Metast Rev 2003; 22: 259-269.

8. Scott AM, Wiseman G, Welt S, Adjei A, Lee FT, Hopkins W, Divgi CR, Hanson LH, Mitchell P, Gansen DN, et al. A Phase I dose-escalation study of sibrotuzumab in patients with advanced or metastatic fibroblast activation protein-positive cancer. Clin Cancer Res 2003; 9(5): 1639-1647.

9. Lee J, Fassnacht M, Nair S, Boczkowski D, Gilboa E. Tumor immunotherapy targeting fibroblast activation protein, a product expressed in tumor-associated fibroblasts. Cancer Res 2005; 65(23): 11156-11163.

10. Loeffler $M$, Krüger JA, Niethammer AG, Reisfeld RA. Targeting tumor-associated fibroblasts improves cancer chemotherapy by increasing intratumoral drug uptake. J Clin Invest 2009 Feb; 119(2): 421-421.

11. Delacher $S$, Derendorf $H$, Hollenstein $U$, Brunner $M$, Joukhadar C, Hofmann S, Georgopoulos A, Eichler HG, Muller M. A combined in vivo pharmacokinetic-in vitro pharmacodynamic approach to simulate target site pharmacodynamics of antibiotics in humans. $J$ Antimicrob Chemother 2000; 46: 733-739.

12. Ikawa K, Morikawa $N$, Ohge $H$, lkeda $K$, Sueda $T$, Taniwaki M, Kurisu K. Pharmacokineticpharmacodynamic target attainment analysis of meropenem in Japanese adult patients. J Infect Chemother 2010; 16: 25-32.

13. Fielding RM, Singer AW, Wang LH, Babbar S, Guo LS. Relationship of pharmacokinetics and drug distribution in tissue to increased safety of amphotericin $B$ colloidal dispersion in dogs. Antimicrob Agents Chemother 1992; 36: 299-307.

14. Jones G. Pharmacokinetics of vitamin $D$ toxicity. Am J Clin Nutr 2008; 88: 582S-586S.

15. National Institute of Health, USA. Public health service policy on humane care and use of laboratory animals; 2002.

16. Gao F, Li L, Zhang H, Yang W, Chen H, Zhou J, Zhou Z, Wang $Y$, Cai $Y$, Li X..Deoxycholic acid modifiedcarboxymethyl curdlan conjugate as a novel carrier of epirubicin: In vitro and in vivo studies. Int $\mathrm{J}$ Pharm 2010; 392: 254-260. 